\title{
Nurturing the Journal of Quantitative Criminology Through Late Childhood: Retrospective Memories (Distorted?) from a Former Editor
}

\author{
John H. Laub
}

Published online: 23 September 2010

(C) Springer Science+Business Media, LLC 2010

I am delighted to be part of the 25th anniversary celebration for the Journal of Quantitative Criminology. Twenty-five years! Where did the time go? I served as Editor of JQC from July 1991 to September 1996, roughly years seven and half through 12 in the 25-year life span. In other words, what life-course researchers call "late childhood". Of course, huge credit must go to James Alan Fox who birthed this journal in 1985 and stayed awake all hours nurturing it through infancy and early and middle childhood. By the time I was on the scene, $J Q C$ was walking tall, already accomplished yet with room to grow and flourish as she did.

In thinking about what to say in these pages, I decided to go back and reread my "From the Editor" statement for my first volume, \#8. At the time, I believed that there was the perception in the field that $J Q C$ was an excellent journal, but only interested in publishing papers that employed the most sophisticated, cutting edge statistical techniques available at time. Like most perceptions (misperceptions?), there was some truth to this one. I saw my task as a new Editor to convince the field that the mission of $J Q C$ was "to publish the best empirical research in the field of criminology and criminal justice" (1992: 153). I believed then and do so now even more strongly that "It is far more important... to let the research question dictate the choice of the analytic technique rather than the other way around" (1992: 153). This means that in many cases, important research questions can be answered using simple methods.

Based on the available evidence, it does appear that I was successful in attracting a wider audience of empirical researchers to $J Q C$ during my editorship. During my first year as editor, $75 \%$ of the papers we published (excluding the special issue) were "new authors" to JQC. This trend continued in my second year, wherein $83 \%$ of the papers were by "new authors". JQC was publishing a larger base of quantitative researchers and in turn $J Q C$ was exposed to a wider audience in the field of criminology and criminal justice. Whether this improved the journal and the field at large, I leave to others to assess.

During my tenure as editor, I was responsible for five volumes (Volumes 8 through 12) that contained nearly 75 papers and three special issues-the first was on quantitative

J. H. Laub $(\bowtie)$

University of Maryland, College Park, MD, USA

e-mail: John.Laub@usdoj.gov 
research in the Netherlands (Volume 8, Number 1), the second focused on gender, crime, and criminal justice (Volume 9, Number 4), and the third was on quantitative research and criminal justice policy in Australia (Volume 11, Number 3). I also encouraged and helped initiate a fourth special issue on crime, victimization, and sentencing in Israel, which was published in the first year of Mike Maltz's editorship (Volume 13, Number 1).

\section{Quantitative Criminology: Past, Present, and Future}

Although largely unrecognized, quantitative research in criminology has a long tradition dating back to Europe (see, for example, Adolphe Quetelet's Research on the Propensity for Crime at Different Ages, (1833) and Charles Goring's The English Convict: A Statistical Study, 1913). Quantitative work also appeared in the United States (see, for example, Clifford Shaw and colleagues Delinquency Areas, (1929) and extensive research on criminal careers by Sheldon and Eleanor Glueck culminating with Unraveling Juvenile Delinquency, 1950). Thus, contrary to conventional wisdom, criminology did not become quantitative when economists began studying deterrence in the 1960s.

In 1985, Jamie Fox launched the Journal of Quantitative Criminology. His argument for a new journal devoted to quantitative work rested on the growing sophistication of quantitative work in criminology and criminal justice and the fragmentation of this kind of research across many journals in the field. In his Introductory Statement in the first issue, Jamie wrote, "Hopefully, the establishment of the Journal of Quantitative Criminology will provide a needed forum to bring together empirical and methodological advances being made in a number of scholarly traditions" (1985: 1). True to form, Volume 1, Number 1, featured empirical papers by operations researchers, economists, and sociologists. Drawing from the best empirical research on crime and criminal justice, regardless of disciplinary home, continued at $J Q C$ under all of the editors.

Over the last 25 years, there have been remarkable advances in quantitative criminology. Not only are there more data to be analyzed because of data archives like ICPSR and other electronic media, we have also witnessed the development of more sophisticated and wide ranging data collection strategies. Here I am thinking of the multiple kinds of data being collected in the Project on Human Development in Chicago Neighborhoods (e.g., in-home interviews and assessments, community surveys, systematic social observation, community informant surveys, census data, and institutional records from the police and schools). Also, we are witnessing in social sciences more and more data collection efforts focused on genetics. At the same time, more powerful data analytic techniques have been developed and employed in research in criminology and criminal justice. This is especially true with regard to the analysis of longitudinal data in a dynamic life course framework.

Yet we have to ask, despite the amazing gains, where does quantitative criminology need to go next? Here I examine the following question: What is the role of quantitative criminology in theory, research, and policy?

\section{Theory}

In my Sutherland address to the American Society of Criminology, I wrote about the bankruptcy of method without theory (see Laub 2006 for details). This applies to all methods, quantitative or not. Despite a rich set of quantitative methods, without theory scientific explanation is not possible. As Per Olof Wikstrom has argued, "empirical 
research can establish correlations, allow us to make predictions, and sometimes demonstrate causes by manipulation (experimentation). However, only theory can provide explanation by answering why questions (why does X cause $\mathrm{Y}$ ), and thereby, specifying how the studied outcome is produced by the putative cause" (2006: 8, emphasis in original). Thus, theory must be intimately connected to empirical research and empirical research must be intimately connected to theory. In this spirit, quantitative methods are tools for both theory and research and are not and can never be ends in themselves. Moreover, it is not healthy for the field of criminology and criminal justice to privilege a specific statistical approach (e.g., Hierarchical Linear Modeling) or a specific research design (e.g., Randomized Control Trials).

What quantitative criminology lacks is an organizing theoretical framework that can tie the disparate parts together. While there have been some attempts to do this recently, none of the efforts have been successful.

\section{Research}

Within quantitative criminology there has been a strong shift from research design to statistical methods. So much of our work focuses on the application of statistical methods that we often lose sight of the importance of asking good research questions. Moreover, there needs to be more candid discussion about the validity and reliability of the data we use in our empirical studies.

In addition, I believe we have lost what I would call descriptive quantitative criminology. At times I wonder if we knew more about the nature of crime and the characteristics of offenders and victims 30 years ago than we do now. Here am I thinking of the ground breaking descriptive studies of Marvin Wolfgang and colleagues at the University of Pennsylvania. Wolfgang began this tradition with his book, Patterns of Criminal Homicide (1958). Others at Penn examined other types of crime in excruciating detail. Thankfully, the Blocks continued and expanded this line of work studying homicide in Chicago. Wolfgang and his colleagues (1972) turned their descriptive lens to the Philadelphia Birth Cohort Studies where we learned enormous bits about the patterning of criminal careers. This descriptive work has appeared again recently with the detailed analysis of the Cambridge Data by Alex Piquero, David Farrington, and Al Blumstein (2007). During the 1970s, descriptive studies by Michael Hindelang and colleagues at the State University of New York at Albany informed us about patterns of criminal victimization using the newly created National Crime Survey data on victimization (see, for example, Hindelang 1976). My question is whither descriptive criminology? Is it possible that we know less about the basics because of our ability to run complicated statistical models with a point and a click?

\section{Policy}

As I discussed in my presidential address to the American Society of Criminology, I have been deeply troubled by past and current public discourse on crime (see Laub 2004 for details). As individuals and as a field, we need to do much more to contribute effectively to the discourse on crime, both at the policy level and with the general public. Part of the problem lies within ourselves. Too often we are writing more and more about less and less. Imagine how much better the field would be if we followed the principle offered by 
Dr. Anthony Fauci, the Director of the National Institute of Allergy and Infectious Diseases. In discussing science, Dr. Fauci stated that what we need is "precision of thought and economy of expression".

Yes, it is the case that in order to enhance policy and practice one needs sound empirical research. Moreover, much of the better research informing policy is based on quantitative methods (e.g., research on hot spots). At the same time, our influence on policy suffers not because of our methods, but because we lack ideas and the ideas we do have are often buried in statistical minutiae. Ultimately, the challenge for criminology writ large is an intellectual one and a desire to reach a broad audience outside of the academy.

\section{Coda}

I want to take this opportunity to thank Jamie Fox for inviting me to be the second editor of $J Q C$. I am sure in the eyes of many in the field, I was not an obvious choice or perhaps not even a wise choice. Fortunately for me, Jamie believed otherwise. Jamie was a wonderful asset to me, especially during my first year as editor, and I cannot thank him enough for his support and guidance. I also want to acknowledge the assistance of the $J Q C$ editorial board throughout my five-year term. Without their helpful guidance, sound advice, and continued encouragement, I could not have performed the editorial tasks as required.

Acknowledgments I thank Dave Kirk and Rob Sampson for their comments on an earlier version of this paper.

\section{References}

Fox JA (1985) Introductory statement. J Quant Criminol 1:1-2

Glueck S, Glueck E (1950) Unraveling juvenile delinquency. Commonwealth Fund, New York

Goring C (1913) The english convict: a statistical study. His Majesty's Stationery Office, London

Hindelang MJ (1976) Criminal victimization in eight american cities: a descriptive analysis of common theft and assault. Ballinger, Cambridge

Laub JH (1992) From the editor. J Quant Criminol 8:153-154

Laub JH (2004) The life course of criminology in the United States. The American society of criminology 2003 presidential address. Criminology 42:1-26

Laub JH (2006) Edwin H. Sutherland, the Michael-Adler report: searching for the soul of criminology seventy years later. The American society of criminology 2005 Sutherland address. Criminology 44:235-257

Piquero A, Farrington D, Blumstein A (2007) Key issues in criminal career research: new analyses of the Cambridge study in delinquent development. Cambridge University Press, Cambridge

Quetelet A (1833) Research on the propensity for crime at different ages, 2nd edn. M. Hayez, Printer to the Royal Academy, Brussels

Shaw CR, Zorbaugh F, McKay HD, Cottrell LS (1929) Delinquency areas. University of Chicago Press, Chicago

Wikstrom PH (2006) Individuals, settings and acts of crime: situational mechanisms and the explanation of crime. In: Wikstrom PH, Sampson RJ (eds) Crime and its explanation: contexts, mechanisms, and development. Cambridge University Press, Cambridge

Wolfgang ME (1958) Patterns in criminal homicide. University of Pennsylvania Press, Philadelphia

Wolfgang ME, Figlio RM, Sellin T (1972) Delinquency in a birth cohort. University of Chicago Press, Chicago 